\title{
NOVAS TENDÊNCIAS TERAPÊUTICAS DE ENFERMAGEM- TERAPIAS NATURAIS - PROGRAMA DE ATENDIMENTO
}

\author{
NEW THERAPEUTIC TRENDS IN NURSING - NATURAL THERAPIES - \\ ASSISTANCE PROGRAM \\ NUEVAS TENDENCIAS TERAPÉUTICAS DE ENFERMERÍA - TERAPIAS \\ NATURALES - PROGRAMA DE ATENCIÓN
}

\author{
Marisa Toshiko Ono Tashiro' \\ Rosane Orlandi ${ }^{2}$ \\ Rita de Cassia Tappie Martins ${ }^{3}$ \\ Ednei dos Santos ${ }^{4}$
}

\begin{abstract}
RESUMO: O presente estudo relata a experiência vivenciada pelos enfermeiros na Clinica de Enfermagem do Campus Universitário do Grande ABC (UniABC), utilizando as terapias naturais: balanceamento muscular, acupuntura e reflexologia como ações terapêuticas de enfermagem. Conclui ressaltando a relevância da aplicação técnico-cientifica no desenvolvimento das atividades de enfermagem e a sua conseqüente repercussão no cuidado de enfermagem.
\end{abstract}

PALAVRAS-CHAVE: clinica de enfermagem, terapias naturais, ações terapêuticas de enfermagem

\section{INTRODUÇÃO}

A criação da Clínica de Enfermagem da UNIABC foi desenvolvida pela necessidade sentida pelos professores e pela procura da comunidade que solicitava alguns serviços como orientação para o autocuidado: hipertensão, diabetes e equilibrio corpo e mente. Razão pela qual se procurou organizar atividades específicas de acordo com a especialidade de cada docente. Neste contexto, foram organizados grupos de atendimento como o de terapia natural que tem assistido inúmeros pacientes com problemas relevantes: físico/psiquico.

A enfermagem utilizando tecnologias naturais busca promover a consciência corporal e um atendimento "holístico". O corpo humano é um campo bioeletromagnético, pulsante que interage com o meio de modo particular e essa inter-relação altera o equilibrio do indivíduo em distintos niveis; neste particular, a relação corpo/movimento/ energia e mente é enfocada.

O homem é um processo em desenvolvimento cuja aprendizagem inicia-se desde a formação das células e dos órgãos que, gradativamente, adquirem habilidades psicomotoras pela aquisição do conhecimento, pela extensão dos relacionamentos e experiências que se denominam "saber, aprendizagem". Essa formação equilibra-se, quando é adquirida em um meio ambiente cultural, social legitimo. O processo de crescimento é um continuo e sofre alterações durante sua vida. $\mathrm{Na}$ ocorrência de um desequilibrio, podem se desencadear experiências negativas e, conseqüentemente, distúrbios de ordem emocional e até físicos. As manifestações e alterações orgânicas são representadas pelo físico: como a postura, o

\footnotetext{
'Enfermeira, Mestre na Saúde do Adulto, Prof. Adjunto da Universidade do Grande (UniABC) São Paulo - Ex-docente da UNIFESP, São Paulo.

${ }^{2}$ Enfermeira, Prof. da Universidade do Grande ABC- (UniABC) São Paulo.

${ }^{3}$ Profa Dra Coordenadora do Curso de Graduação em Enfermagem da Universidade do Grande ABC- (UniABC) São Paulo.

${ }^{4}$ Enfermeiro, Prof. Auxiliar da Universidade do Grande $A B C$.
} 
caminhar, o sentar, o olhar, o falar, enfim, vários são os movimentos. O fisico adquire a postura que a vida oferece: social, politica, ideológica e histórica. O ser humano busca valor, poder, prestigio e bens materiais e nega o equilibrio do corpo, transgredindo as expressões intimas, sobretudo, em sua aceitação social. As imposições oferecidas ao corpo, eventualmente, podem alimentar medo, fuga, ressentimento, raiva e disfarce, impedindo o crescimento e distanciandose de seus objetivos individuais e culturais.

No desenvolver pessoal e profissional do individuo, este, quando é pressionado por uma atitude imperiosa, reage sofrendo bloqueio ou frustração em seus mais fortes desejos, consumindo uma energia considerável para proteger-se do ritmo de vida que lhe apresenta. Esta proteção aos sofrimentos e atitudes diante dos fatos caracteriza a estrutura da personalidade que, muitas vezes, é preocupante.

De acordo com Horta e Horta (1999a), a globalização é o enfoque principal, acreditase que o ser humano deva ser analisado e tratado em um contexto: ser assistido como um ser integral e integrado ao meio ambiente que o envolve. As terapias naturais lidam com a energia, falta e excesso e tratam a sintomatologia, estudam meridianos correspondentes aos órgãos e percebem as alterações orgânicas, metabólicas e estruturais.

$\mathrm{Na}$ India, China e Japão, a teoria da energia vital, a energia Qi em chinês, é bastante desenvolvida. Acreditam que o ser humano existe única e integralmente, em função dessa energia que percorre o corpo de maneira organizada, simples e definida. A cultura brasileira ainda está embasada e valoriza a medicina alopata, onde se trata apenas a doença, esquecendo o homem como um todo (HORTA; HORTA, 1999b, p. 4).

Embora se atribua pouco valor ao aspecto cultural, pensou-se em dar os primeiros passos do cuidado holistico, ao se utilizar as terapias naturais que abrangem o fisico e o psiquico. Considerando-se que o ser homem é constituido de células energéticas que desempenham funções orgânicas e metabólicas, quando se apresentam em equilibrio, esta harmonia energética rege atividades da vida diária: fisicas, intelectuais e emotivas sem estresses. Quando ocorre o desequilibrio, das energias, este se manifesta no corpo físico em forma de dor, cansaço, irritação, depressão, entre outros.

\section{PROGRAMA ASSISTENCIAL DE ENFERMAGEM}

A clinica de terapia natural é constituida por três áreas de atuação:

- Balanceamento muscular (BM)

- Acupuntura

- Reflexologia

\section{DESCRIÇÃO DAS ÁREAS}

\section{Balanceamento muscular}

Na década de 60, a técnica de BALANCEAMENTO MUSCULAR foi desenvolvida na Estados Unidos, por George Goodeheart, com o nome de APPLIED KINESIOLOGY (cinesiologia aplicada) que verificou ser possivel ativar/desativar o funcionamento dos músculos do corpo por meio de pontos reflexos, descobertos no início do século pelos médicos Chapmann (reflexos neurolinfáticos) e Bennett (reflexos neurovasculares) Horta (2000).

O balanceamento muscular é uma técnica que vem sendo estudada por pesquisadores como Topping, Callahan, Walther e outros; identifica os bloqueios da energia vital que percorrem 
o corpo humano e o mantém vivo. Os testes musculares foram desenvolvidos e verificou-se ser possivel testar e corrigir eventuais bloqueios de "ENERGIA VITAL", reorganizando seu fluxo no corpo humano (HORTA; HORTA, 1999a).

Diante dos resultados positivos, a técnica era e é utilizada e praticada em todo mundo por diversos profissionais: médicos, dentistas, quiropráticos, osteopatas, fisioterapeutas, psicoterapeutas, nutricionistas, pedagogos e outros. Para estes profissionais, o teste muscular é considerado como a ferramenta mais segura para identificação e desativação de bloqueios no sistema corpo/mente e é bastante preciso.

Conhecendo a técnica, percebeu-se que os enfermeiros poderiam utilizá-la para amenizar a dor, os estresses, agir no pré e pós-operatório em doenças crônicas e agudas, entre outras, de forma muito simples, sem nenhum processo invasivo, proporcionando bem-estar, conforto e tranqüilidade aos indivíduos. É possivel fazer a manutenção da saúde pelo controle de fluxo de Energia Vital, desbloqueando as áreas de tensão, evitando doenças e estresses.

As técnicas de balanceamento muscular são simples de fácil aprendizagem e aplicação, não envolvem tratamento médico ou quaisquer técnicas médicas. Os testes musculares são usados para identificar a qualidade e a quantidade de "ENERGIA VITAL" que alcança um determinado ponto do corpo de uma pessoa. Esta se constitui em uma técnica que não necessita de controle alimentar e equipamentos especializados. $O$ tratamento e sua periodicidade são analisados pelo teste muscular "o corpo responde". As únicas ferramentas adotadas são as mãos para tocar pontos prédefinidos do corpo, cuja localização e utilização foram descobertas ao longo destes trinta anos (HORTA; HORTA, 1999a).

O balanceamento muscular trabalha com 14 músculos principais e 28 secundários. Cada um corresponde a um determinado meridiano e órgão. Após, testar-se cada músculo, as correções correspondentes são feitas. O corpo diz tudo. Quando a correção do músculo desligado ou desbalanceado é feita, "desperta e acelera a capacidade do ser humano de tornar-se consciente, obter a harmonia de seu corpo e permitir, com isso, que seja melhorada a capacidade de resistência às agressões a que cotidianamente o corpo está sendo submetido" (HORTA; HORTA, 1999a:5).

Aqueles que conseguem compreender o ser humano como um todo, com responsabilidade por sua saúde e bem-estar se interessam por essa energia, pois sabem que se houver equilibrio de energia, não haverá efeitos colaterais, nem implicará desgaste físico ou perda de energia.

\section{Acupuntura}

Trata-se de uma técnica milenar da medicina tradicional chinesa, atualmente utilizada em vários paises que despertou curiosidade e estimulou os estudiosos a pesquisá-las culminando na recomendação pela ONU como técnica eficiente na prevenção de doenças. Apresenta como base os principios que norteiam a medicina tradicional chinesa, composta por outras técnicas como: ventosa terapia, moxabustão, massagem, tui-ná, massagem chinesa, quioprática chinesa (manipulação osteoarticular), fitoterapia chinesa, Qi Qong (exercícios terapêuticos), tai-chichuan (exercícios chineses). Todas estas técnicas são usadas com sucesso há 4.000 anos para tratamento de várias patologias. A acupuntura emprega uma faceta da medicina tradicional chinesa e um de seus pilares é a teoria do Yin/Yang, Outro é a teoria dos canais e colaterais (meridianos), que em número de 14 estão de tal forma envolvidos, que constituem uma verdadeira "malha energética" espalhada pelo corpo.

A prática da acupuntura consta da colocação de agulhas de prata, ouro, bronze, cobre ou inox em pontos especificos localizados nos meredianos de energia, espalhados em simetria pelo corpo. Com o emprego de agulhas inseridas no corpo, com a finalidade de ocar pontos especificos e fazer o Qi (energia) seguir pelos trajetos (meridianos) (HIDETARO,1994). 
Ainda a pressão digital pode ser utilizada nos mesmos pontos, produzindo algum efeito sedativo ou estimulante. Atualmente a acupuntura é reconhecida como especialidade para os enfermeiros pelo Conselho Regional de Enfermagem - COREn (2001) na Resolução 197/1997.

\section{Reflexologia}

É a ciência que lida com o principio de que nos pés e nas mãos existem áreas de reflexos que correspondem a todos os órgãos, glândulas e partes do corpo. É um método singular que utiliza o polegar e os dedos nestas áreas de reflexo. Constitui uma forma de terapia absolutamente segura, além de ser uma experiência muito relaxante e agradável seus objetivos são: normalizar as funções do corpo, relaxar as tensões e melhorar a circulação sanguinea e o sistema nervoso, esta terapia é eficaz em adultos e crianças de todas as idades (BYERS, 1995, EREDE, 1998, GRAHAM, 1998).

As metodologias descritas acima e fundamentadas por George Goodhearth citado por Horta e Horta (1999a) ao associar os pontos da acupuntura com os pontos reflexos que servem de base para a prática de enfermagem desenvolvida na Clinica de Enfermagem da Universidade do Grande ABC.

Este estudo busca discutir os mecanismos fisiológicos, psicológicos e energéticos da terapia natural e a fundamentação dos resultados obtidos, desenvolvendo ações de enfermagem com base metodológica própria e abordagem holistica nos grupos terapêuticos.

\section{AÇÕES DE ENFERMAGEM}

\section{ASSISTENCIAL}

O principio básico sobre o qual se fundamenta a terapia natural, cuida do corpo transpessoal no processo de enfermagem, é baseada na cinesiologia aplicada que objetiva o restabelecimento integral do corpo/mente.

A enfermagem busca promover uma integração do ser humano com o ambiente, reequilibrando os campos energéticos pelos desbloqueios emocionais, fisicos e quimicos e mantendo o fluxo de energia estável ou equilibrado

A assistência de enfermagem trabalha com músculos, meridianos, toques, digitopressura e programação neurolingüistica, florais de Bach, entre outros. Permite perceber a capacidade corporal, mental e emocional aumentando o potencial de consciência a respeito de si próprio.

O balanceamento muscular, em especial, procura harmonizar ou clarificar a mente, desenvolvendo uma percepção maior quanto aos sentimentos, ao querer, às dores e aos sofrimentos e permite, assim, um caminho diferenciado para o autoconhecimento Horta e Horta (1999b, 2000).

A assistência de enfermagem ao empregar o balanceamento muscular faz um diálogo com o corpo por intermédio do uso do teste muscular; que nos oferece uma resposta precisa e permite uma comunicação direta com o corpo que reconhece e revela precisamente onde reside o bloqueio e o que precisa para eliminá-lo como tensão.

Estudiosos como Thie (1979), Horta e Horta (2000) consideram o teste muscular como a ferramenta mais segura para identificação e desativação de bloqueios no sistema corpo/ mente, cujo uso torna a técnica do balanceamento muscular única em sua visão de mundo, norteia a conduta do enfermeiro, permite associar outras técnicas como "Stress" "Barômetro comportamental" e métodos: fisicos, emocionais e mentais, identifica o desequilibrio prioritário, pois funciona sobre os estresses do sistema.

O teste muscular é "o método de análise utilizado para determinar em que ponto do 
corpo o fluxo de 'energia vital' está obstruido, que chama atenção do corpo para o músculo, de modo a identificar se o músculo está 'ligado' ou 'desligado', ou seja, se ele está com capacidade para executar os movimentos para os quais o corpo desenvolveu esse músculo ou não". "Se o músculo estiver desligado isso indicará um bloqueio na "energia vital", pois não está alcançando esse músculo de forma adequada"e ainda "aqueles que apresentarem menos de $90,0 \%$ de sua capacidade", se estiverem ligados, o músculo estará sem bloqueio. (HORTA e HORTA, p. 3, 1997).

Horta (2000, p. 4) descreve que o "teste muscular não tem a finalidade de medir a 'força' da pessoa, mas tão somente medir o tônus muscular, o que não envolve a utilização de 'força' nem pelo testador, nem por quem está sendo testado". As correções e os tratamentos realizados podem ser aplicados de uma forma geral, assim, profundas mudanças na vida do individuo ocorrerão baseadas no reequilíbrio energético.

Com relação à acupuntura, o enfermeiro identifica excesso e falta de energia nos meridianos e correlaciona-os com os sinais e sintomas, na tentativa de reequilibrar o sistema energético. O procedimento empregado é a inserção de agulha nos pontos de acupuntura.

A reflexologia é a linguagem do tato que procura identificar pontos doloridos e massageá-los, com fins terapêuticos. Cada região do pé apresenta uma relação com órgãos de modo que seja possivel aliviar a sintomatologia e promover o relaxamento corporal e mental (GILLANDERS, 1999).

Depois de algum tempo assistindo e observando o cliente, desenvolvendo pesquisas e estudando metodologias na área de terapia natural, acreditamos que o cuidado holístico é possivel, pois a terapia natural lida com a energia. Nesta ótica, o cuidado de enfermagem não está voltado à doença, e sim, à forma como vivencia a saúde, doença e seu dia -a- dia, tais como: o enfrentamento traduzido pelas linguagens verbal e não-verbais de seu próprio corpo.

Cuidar com base em um sinal não nos é relevante, porque o corpo interage com o ambiente na totalidade do ser, envolvido de nervos, pele, músculo e sangue para expressar e sentir suas emoções e, nesse mesmo corpo, o enfermeiro busca transcender aquilo que 0 cliente não conhece, aplicando a terapia natural, mostrando pelo toque físico que é possivel despertar o sistema energético, indo além do tradicional de nossa prática, pois o Homem é holodinâmico.

Segundo Weile Crema (1993, p. 50), a holodinâmica apresenta três aspectos potenciais inseparáveis : 'holoespacialidade' que os tibetanos chamam de "gshi", ou espaço primordial, que não é vazio; este emite uma ' holorradiação' que se distribui em campos de irradiação, cada um com sua freqüência luminosa; para o Ser passar a existir, a holorradiação carrega consigo uma qualidade inteligente que "contém o potencial da holoprogramação" do que chamamos de existência, que é a garantia de conhecimento". O dialogar com o corpo é o principio não fragmentado da energia: a holorradiação, "segundo esse principio, matéria, vida e consciência são inseparáveis e constituidas da mesma energia".

Refletindo sobre a terapia natural, esta permite um olhar holistico, pois, analisa a estruturas fisiológicas, quimicas e emocionais em razão da trama sináptica do corpo e as causas primárias da doença nem sempre são óbvias. Procura identificar a idade causa e desativar os bloqueios e, integrar os sistemas de modo harmônico, trabalhando sempre num sistema de prioridades.

Conforme relata Horta (2000) quando a capacidade funcional de uma área do corpo é excedida, este compensa essa atividade com outros mecanismos. Desse modo, aparecem as dores, entorses, rotações das estruturas musculares e ósseas do corpo. Estes mecanismos ocorrem sem que o consciente da pessoa perceba o que está acontecendo, pois existem a necessidade e a capacidade de sobrevivência, acima de qualquer prioridade. Para "sobreviver", 
o corpo torce, emperra, dói para se manter vivo, o que é a prioridade principal. Assim, vai se "desligando" progressivamente de seus sistemas menos necessários, quando sua capacidade funcional vai sendo ultrapassada. Como cuidado, os sistemas do corpo devem ser "religados", também, dentro de prioridades que variam de pessoa para pessoa. A compreensão disso faz com que as correções tornem-se extremamente simples, pois ao tentar corrigir algo não prioritário, o corpo reage de forma negativa, não aceita a correção ou faz com que esta não permaneça por muito tempo.

O Homem e o Universo compartilham de uma trama de informações positivas e negativas que contribuem para a formação da doença. Quando este não consegue eliminar fatos e experiências vividas, faz o registro de memória e arquiva em seu próprio corpo.

Ao cuidar de clientes com problemas de saúde não se pode desvincular corpo e mente de seu ambiente. A enfermagem deve atuar de forma holistica, agindo de modo amplo, integrado, relacionando a teoria à prática, determinando suas ações e intervindo, pois é o próprio profissional que executa a técnica e o corpo mostra onde reside seu problema e como corrigi-lo. Desse modo acreditamos que o enfermeiro poderá executar a função de "cuidar do paciente".

Para realizar a terapia natural é importante:

- O enfermeiro lidar diretamente com o cliente, observar a preocupação do todo interagir mutuamente, até mesmo com o ambiente.

- Deve conhecer os passos para iniciar o balanceamento muscular, a acupuntura e reflexologia.

\section{A ARTE DA TERAPIA NATURAL BUSCANDO FORMAS DE CUIDAR}

\section{Orientação aos clientes para o autocuidado com relação à:}

Alimentação - como já foi referido, o corpo responde pelo teste muscular, pela energia Yin/Yang e pelo tato. É possivel identificar os alimentos que os clientes podem ou não ingerir pelo teste muscular. O teste é realizado da seguinte forma : o cliente segura um determinado alimento e aplica-se o teste muscular, caso seja debilitante ao corpo, este se desliga. Dessa forma, é possivel orientar quais os alimentos que o cliente pode ingerir e a quantidade, inclusive; e semanalmente deve-se fazer uma avaliação em grupo.

A relação social é um dos problemas mais sérios observados durante as terapias naturais. Os clientes têm dificuldade de trabalhar o emocional sobretudo com a familia e acabam arquivando memórias negativas no corpo, deformando-os. Para ajudar o equilibrio dessas emoções, atualmente, trabalhamos com os exercicios de equilibrio fisico-emocional que denominamos de ginástica cerebral, uma forma de harmonizar os dois hemisférios, pois lidamos, especialmente, com pessoas idosas, algumas crianças com dificuldade no aprendizado.

Durante as terapias de balanceamento muscular, acupuntura e reflexologia se conversa muito com os clientes, de modo, ser possivel reconhecer as dificuldades de relacionamento pessoal, familiar e de trabalho, criando estratégias de equilibrar o corpo e mente.

Formação de grupos para tratamento de um sintoma especifico: grupo de dor; grupo de enxaqueca; grupo de plaquetopenia. A idéia de criar grupos com problemas semelhantes têm o objetivo de trabalhar as mesmas sensações e mostrar que a própria pessoa consegue desbloquear, utilizando a técnica ensinada, até mesmo, trocar idéias e experiências vivenciadas. As reações podem se manifestar de forma semelhante na pele, na cabeça, na 
respiração e no corpo.

Observa-se que estas manifestações ocorrem em razão da liberação de estresse fisico e mental. A enxaqueca está relacionada à caracteristica de personalidade "o confronto" e, para isso, usamos a técnica de desativação de estresse pelo circuito dos olhos associada à técnica de alivio de tensão.

Com relação a plaquetopenia, trabalhamos "a separação" de pais, ambientes e amigos. Percebemos que a trama da separação está no subconsciente, pois não se relaciona com o fato. Para sua desativação, procuramos identificar a pessoa e o que causou, normalmente, é a palavra "incomodar", para desativação usamos a mesma técnica da enxaqueca, porém com o cuidado de avaliar a pele e as ocorrências que se sucedem de uma avaliação para outra.

Com relação ao grupo de dor, preconiza-se ensinar a limpeza do meridiano de acupuntura, segundo Horta (2000) "quando se tem uma sensação de dor , essa sensação é transmitida ponto a ponto pelos meridianos de acupuntura que passam pelo local de dor ou que passam perto dolocal de dor. Para aliviar a dor basta interromper a transmissão do estimulo de dor que percorre o meridiano e vai para os centros de identificação de dor existentes no cérebro". Localiza-se e aviva-se a dor com uma mão, identifica-se o meridiano com a outra mão percorre-se o meridiano, quando chegar no ponto da dor, mantém-se a mão fixa por 20 a 30 segundos e com a outra continua percorrendo o meridiano até seu final. O tapotamento do meridiano, também, é feito e durante dois minutos seu inicio e o final são tapotados.

\section{CONSTRUÇÃO DE AÇÕES DE ENFERMAGEM}

\section{A terapia natural pode ser aplicada em qualquer situação?}

Em primeiro lugar, devemos sempre observar as condiçōes fisicas e clinicas do cliente. Este deve estar consciente e aceitar a terapêutica, especialmente, o balanceamento muscular, pois a técnica dialoga com o corpo. Caso o cliente não reconheça o cuidado, deve-se parar de imediato. Com relação à reflexologia, se o cliente tiver algum dano músculo esquelético na região, esta deverá ser evitada.

\section{A indicação da terapia natural}

É um assunto muito polêmico, pois os profissionais em sua maioria não perceberam ainda a importância de trabalhar o sistema energético, surgindo dúvidas sobre sua eficácia ou não. A acupuntura é bastante aceita tanto pelos profissionais como pela população, não havendo nenhuma contra indicação. No Brasil, o balanceamento muscular è uma técnica nova e poucos profissionais a conhecem. A indicação da terapia é a todas as pessoas, desde o feto até o idoso. A única ressalva que fazemos é diante de pessoas que se submeteram ao tratamento de quimioterapia, parece que o efeito da técnica não é tão eficaz, pois relaciona-se com a destruição de células, pois são transmissores de energia e informação pelo corpo. A reflexologia é relacionada ao toque e massagem nos pés, preocupando apenas com lesão ligamentar, caso contrário, é indicado a todos.

\section{Os efeitos das técnicas sobre a fisiologia humana - procedimentos específicos}

Conscientização corporal - pelas terapias naturais, conseguimos modificar alguns conceitos arquivados no corpo. As técnicas naturais permitem extrair e aprofundar as emoções e a sabedoria do organismo, admitindo o autoconhecimento que é a única fonte 
de informação verdadeira sobre suas experiências individuais de vida.

Relaxamento - os músculos desempenham um papel importante para chegar ao relaxamento; eles nos falam na linguagem do corpo, causam sono, tranqüilidade e conseguem referir-se a problemas que antes tinham dificuldade de relatar. Isto ocorre porque o fluxo de energia começa percorrer sem bloqueios, canalizando a energia para o equilibrio e aliviando as tensões.

Alívio da dor - baseado no momento em que ocorre o desbloqueio do meridiano, provavelmente, proporcionará alivio da dor.

\section{Vantagens e desvantagens da terapia natural}

Trata-se de um cuidado que busca o equilibrio e permite olhar o quê e como escolhe os problemas para enfrentar o seu dia a dia. Sua vantagem é mostrar o que a mente consciente acredita agora e, o que a mente subconsciente nega por causa do medo, da dor, do passado, assim, cria uma realidade que é a maneira de ser e de atuar no mundo. O próprio corpo corrige todas as alterações, é como se fosse uma indústria farmacêutica com todas as substâncias necessárias a um bom funcionamento. Desvantagem é uma terapia que deve feita individualmente, demorando em torno de 45 minutos a uma hora.

\section{ENSINO}

As terapias naturais fazem parte da Disciplina de Fundamentos do Processo de Cuidar do curso de Graduação em Enfermagem da Universidade do Grande ABC - São Paulo. Os alunos fazem estágios durante seis dias letivos com duração de seis horas/ dia, são treinados para realizar algumas técnicas para o cuidado de alguns sinais e sintomas, sem avançar no subconsciente, ficando apenas no físico. Essas podem ser utilizadas no dia a dia do hospital para o cuidado de obstipação, enxaqueca, alivio da dor, hipertensão e insônia.

Trabalha, inclusive, com grupo de idoso treinando o equilibrio mente e corpo pela ginástica cerebral, uma vez por semana, durante uma hora. Nesse momento, o grupo tem a liberdade de relatar as experiências e dificuldades vivenciadas, faz-se um questionamento daquilo que foi ensinado na semana anterior e que é checado por meio de perguntas e demonstração do exercicio.

\section{RESULTADOS - relatos de clientes}

Entendemos que na terapia natural não é possivel aplicar um protocolo, pois tem sido procurada por pessoas que já fizeram vários tratamentos: médico, fisioterápico, psicológicos, sem resultados satisfatórios. Diante disso, destacamos um leque de sinais e sintomas que cada cliente traz consigo, que impossibilitam uma divisão em categorias. Assim descreveremos apenas os sinais e sintomas mais freqüentes atendidos por cada área.

Balanceamento muscular : foram realizadas 98 consultas, com os seguintes sintomas e sinais: dor (cervical, torácica, lombar) e muscular ; LER(lesão por esforço repetitivo); artrite reumatóide; depressão; alergia - púrpura; deformidade fisica, alteração músculo esquelética (osteogênese, escoliose); cefaléia, enxaqueca; insônia; hipertensão;astenia; dificuldade de aprendizagem-memorização; dislexia; tentativa de suicidio e outros.

O balanceamento muscular demonstrou sua eficiência no alivio da dor, das enfermidades relacionadas às funções orgânicas e metabólicas; manteve o individuo "bem" após um trauma de ordem emocional , fisica e intelectual; ajudou na recuperação, preveniu recaídas, após uma 
doença, traumas, depressões e auxiliou na manutenção do bem-estar, entre outros.

Com relaçăo ao emocional podemos citar - a artrite reumatóide é uma doença relacionada à submissão; a cefaléia relacionada ao confronto; a púrpura a separação de algo e outros.

Acupuntura - Foram realizadas 136 consultas. Os principais sinais e sintomas foram : lombalgia, cervicalgia, ombralgia, mialgias, artroses; renites, sinuvites, alergias; dispepsia, anorexia; cefaléia, depressão; hipertensão;insônia, obesidade e outros.

Reflexologia - Foram realizadas 136 consultas. Os principais sinais e sintomas foram assim distribuidos:dor (cervical, torácica, lombar) e muscular; depressão; cefaléia, enxaqueca; Insônia, hipertensão.

Os clientes que se submeteram ao tratamento obtiveram resultados satisfatórios como:

1 - Alivio da dor

2 - Suspensão de medicação tipo: corticóides, analgésicos, antidepressivos e outros. Todos os clientes tinham acompanhamento e as medicações foram suspensas pelo médico.

3 - A maioria relatou sentir bem-estar, após a terapia.

4 - O aumento de produtividade nos afazeres domésticos, escola e trabalho em geral

\section{CONSIDERAÇÕES FINAIS}

A repercussão foi significativa tanto na comunidade acadêmica como na população, pois tivemos que aumentar os dias de atendimento.

Os clientes quando percebiam os efeitos da terapia natural, indicavam outros clientes que buscavam meios para solucionar seus problemas. Alguns clientes relataram que estavam cansados de fazer tratamento alopático que lhes ocasionavam conseqüências graves como úlcera gástrica, em razão da ingestão de vários medicamentos, outros que já se preparavam para cirurgia. Nesses casos, a terapia natural fez apenas a correção do bloqueio e o próprio corpo produziu todos os medicamentos necessários para manter o equilibrio.

Diante destas ponderações, estamos convencidos de que a terapia natural é eficaz e pode ser cuidada, paralelamente, com a alopática.

Acreditamos que o cuidado em paralelo com a medicina tradicional é fundamental, até porque foi um meio de comprovar a eficiência do tratamento pelos exames laboratoriais e radiológicos solicitados pelo médico, observando e analisando todos os tratamentos feitos com a medicação, especialmente, naqueles que já trilharam caminhos diversos à procura de uma solução.

Novos espaços começam a emergir para a profissão, promovendo sua autonomia, por meio de uma ação terapêutica eficiente. Acredita-se que os enfermeiros devam ultrapassar essas barreiras e enfrentar a nova oportunidade que se abre para a profissão, que se vislumbra nesse início de século, caminhando em busca do aperfeiçoamento tecnológico.

Assim, este fato poderá contribuir, para que o profissional de enfermagem possa se inserir de modo participativo e consciente para identificar e conhecer outros problemas de saúde, talvez, desconhecidos pelo próprio paciente, colaborando para aliviar os males do individuo.

SUMMARY: The present study reports the experience lived by the nurses in the Nursing Clinic of the Campus Universitário do Grande $A B C$ (UniABC), using natural therapies: applied kinesiology, acupuncture and reflexology as therapeutic actions of nursing. At last, the study emphasizes the relevance of the technical-specific application in the development of nursing activities and the consequent effect in the nursing care.

KEYWORDS: nursing clinic, natural therapies, therapeutic actions of nursing 
RESUMEN: EI presente estudio relata la experiencia vivida por los enfermeros en la Clinica de Enfermeria del "Campus Universitário do Grande ABC (UNI ABC)", utilizando las terapias naturales: equilibrio muscular, acupuntura y reflexologia como actividades terapéuticas de enfermeria. Se concluye la relevancia de la aplicación técnico-cientifica en el desarrollo de las actividades de enfermeria y su positiva repercusión en el cuidado de enfermeria.

PALABRAS CLAVE: clinica de enfermeria, terapias naturales, actividades terapeúticas de enfermeria

\section{REFERÊNCIAS BIBLIOGRÁFICAS}

CONSELHO REGIONAL DE ENFERMAGEM. Documentos básicos de enfermagem: principais leis e resoluções que regulamentam o exercicio profissional de enfermeiro, técnicos e auxiliares de enfermagem. 1. ed. São Paulo: COREN, 2001

BYERS,D.C. Masaje Reflxologia de los Pios 4. ed. Barcelona: Ibis, 1995.

EREDE,C.B. Masaje Zonal del Pie $2^{\mathrm{a}}$ ed Barcelona: Ibis, 1998.

GRAHAM, L. Alimentação através dos pés. Um manual para a prática de Reflexologia. Barcelona: Ibis, 1998.

GILLANDERS, A. Reflexologia um guia passo a passo. 1. ed. São Paulo:Manole Ltda, 1999.

HIDETARO,M. Introdução à acupuntura São Paulo: Icone, 1994. 159 p.

HORTA,C,; HORTA,M. Balanceamento Muscular - técnicas básicas III. Rio de Janeiro: Instituto Brasileiro do Balanceamento Muscular, 1997. 96 p.

HORTA,C,; HORTA,M. Balanceamento Muscular - técnicas básicas I. Rio de Janeiro: Instituto Brasileiro do Balanceamento Muscular, 1999a. 87 p.

HORTA,C; HORTA, M. Balanceamento Muscular - técnicas básicas V. Rio de Janeiro: Instituto Brasileiro do Balanceamento Muscular, 1999b. 145 p.

HORTA,C,; HORTA,M. Balanceamento Muscular - técnicas básicas V. Rio de Janeiro: Instituto Brasileiro do Balanceamento Muscular, 2000. 145 p.

THIE, J. Touch for Health. CA: Devorss \& Company Publishers, 1979.

WEIL, P. ; D AMBROSIO, U.; CREMA,R. Rumo à nova transdisciplinaridade: sistema aberto de conhecimento. São Paulo: Summus, 1993. 175 p. 